Waste and Resource Management Volume 167 Issue WR4

Recycling glass-fibre-reinforced plastics in the automotive sector

Regenfelder, Faller, Dully et al.

\title{
Recycling glass-fibre-reinforced plastics in the automotive sector
}

Max Regenfelder Dipl.-Oec.

Research Fellow, Graduate School of Excellence advanced Manufacturing Engineering (GSaME), University of Stuttgart, Stuttgart, Germany

Jürgen Faller State-certified Mechanical Engineer

Environmental Coordinator Actuation Systems, Continental Automotive Systems - Division Hydraulic Brake Systems, Continental Teves AG \& Co. oHG, Frankfurt/Main, Germany

Stefan Dully Dr.-Ing.

Environmental Manager in Product Development, Corporate Quality \& Environment - Environmental Management in Product Development,

Continental Teves AG \& Co. oHG, Frankfurt/Main, Germany

Harald Perthes

Environmental Manager in Product Development, Quality Automotive, QEP/ IMDS, Continental Teves AG \& Co. oHG, Frankfurt/Main, Germany
Ian Williams PGCE, PhD, CChem, MRSC, MCIWM, FHEA

Professor of Applied Environmental Science, Centre for Environmental Sciences, Faculty of Engineering and the Environment, University of Southampton, Southampton, UK

Emilia den Boer Dr.-Ing.

Assistant Professor, Institute of Environment Protection Engineering, Section of Waste Technology and Land Remediation, Wroclaw University of Technology, Wroclaw, Poland

Gudrun Obersteiner Dipl.-Ing.

Business Manager, Department of Water, Atmosphere and Environment, Institute of Waste Management, University of Natural Resources and Life Sciences Vienna (BOKU), Vienna, Austria

Silvia Scherhaufer Dipl.-Ing. (FH)

Research Associate, Department of Water, Atmosphere and Environment, Institute of Waste Management, University of Natural Resources and Life Sciences Vienna (BOKU), Vienna, Austria

The automotive sector is facing the challenge to become more resource-efficient in the manufacture of cars and their components. One approach is to increase the share of recycled materials. This paper presents the results of a case study for the automotive sector of the EU-funded Zerowin project. A safety-relevant component of the braking system was selected for manufacture using a mechanically recycled composite plastic material (polyethylene terephthalate reinforced with short glass fibres). The case study demonstrated the interdependencies between material and component specification, component design, material properties and the production process: using recycled glass-fibre-reinforced plastics for a safety-relevant component is not just an issue of input substitution, it is an interplay of technological (product development, production process modification, recycling process), organisational (security of supply, network infrastructure) and economic (material cost savings versus adjustment costs, planning horizons) factors resulting from the input substitution of primary material and changes of material properties. An industrial network was established and the case study's findings were transferred to serial mass production. Industrial networks are seen as an appropriate tool for securing the supply and quality of recyclates from traceable sources.

\section{Introduction: The resource efficiency challenge in the automotive sector}

The automotive sector is facing the challenge to become more resource efficient. Resource efficiency can be improved through different approaches. Within the automotive use phase, various measures have been implemented or imposed by legislation, such as increased use of electric vehicles, lowering gasoline fuel consumption and reducing carbon dioxide emissions per kilometre (EC, 2009, 2012). Extended producer responsibility for end-of-life vehicles (ELVs) - which basically means their recycling - is mandatory in the European Union (EC, 2000). However, the manufacturing stage of the products - the cars - also has to become more resource efficient (Jovane et al., 2009).
The Zerowin project case study reported here was concerned with the automotive sector and focused on an industrial network for mechanical recycling of plastics. It was led by Continental, which was one of the top three worldwide automotive suppliers in terms of revenue in the year 2012. As a systems supplier, Continental was responsible for developing the braking system in which the plastics component considered in this case study was integrated according to the requirements given by the original equipment manufacturers (OEMs). Continental (hereafter called the tier 1 supplier) coordinated the work activities of the tier 2 suppliers and material suppliers. The tier 1 supplier, a plastics component manufacturer (tier 2 supplier), a virgin materials supplier and one pilot OEM customer were involved in the pilot industrial 
Waste and Resource Management

Volume 167 Issue WR4
Recycling glass-fibre-reinforced

plastics in the automotive

sector

Regenfelder, Faller, Dully et al. network that transferred the case study's findings into serial mass production.

For this case study, a safety-relevant component of the braking system was chosen. The component is manufactured from glass-fibre-reinforced polyethylene terephthalate (PET); specifically, PET-GF35 - PET reinforced with short glass fibres to a dosage of $35 \%$ by weight. The component is a safety-to-life piece and will serve as a flagship example for the employability of recycled plastics in safety-relevant applications in vehicles. The performance of the component had to remain unchanged compared with manufacture using virgin materials as a precondition, regardless of whether recycled material was incorporated or not.

The chosen component has high technical material requirements regarding thermal stability, mechanical resistance and shape accuracy. A safety-relevant application was chosen because there is a traditional reluctance and reservation in the automotive industry to use recycled materials in functionally important components, in particular for safety-to-life components.

Nevertheless, the use of recycled materials in vehicles is an issue in today's automotive industry: OEMs have already reported figures for the overall share of secondary plastics or renewable materials, both replacing primary plastics, in their sustainability reports or product datasheets (e.g. BMW, 2011; Daimler, 2011). Becoming more resource efficient is not just about environmental protection - it also affects economic competitiveness. At present, a modern car contains about $40 \%$ recycled material based on total weight and for all employed materials, and the OEMs are aiming to increase this share (Volkswagen, 2012).

Recycled plastics provide significant environmental benefits when used as substitutes for virgin materials (Hopewell et al., 2009; Lazarevic et al., 2010). The recyclate for this case study was reprocessed from production residues or 'sprues'. Before the case study, these sprues were disposed of as waste. Figure 1 shows a typical sprue.

Annual production of the addressed PET-GF35 in Europe is about 3500 t. Compared with the overall consumption of PET in the European automotive industry, which is about $3.9 \mathrm{Mt}$ per year (Plastics Europe et al., 2012), it is a speciality plastics material designed for and to a large extent only used for its safety-relevant use case in braking systems.

Recycled plastics in the automotive sector are mainly thermoplastics. Taking the Mercedes-Benz B-class as an example of a modern car, 75 components, with a weight of $39 \cdot 2 \mathrm{~kg}$, consist at least partly $(100 \%$ recyclate or a recyclate share) of recycled plastics. The share of those components' weights is about $15 \%$ of the total weight of employed plastics (Daimler, 2011). BMW

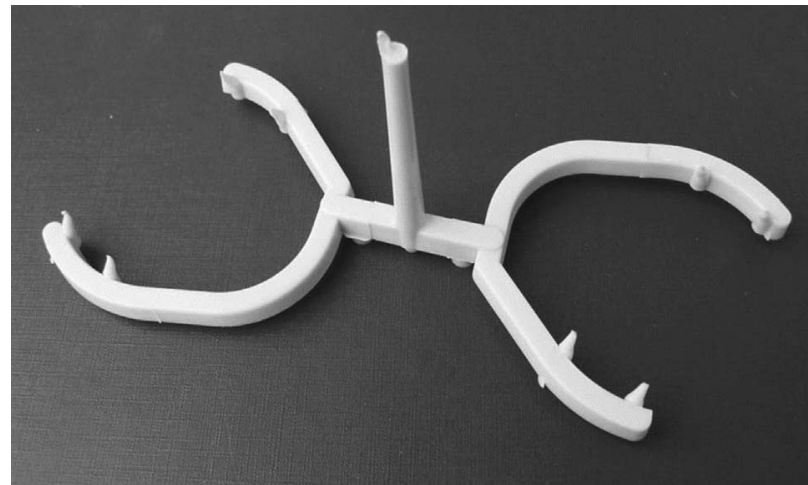

Figure 1. Typical sprue

(2011) states that the recyclate share of up to $15 \%$ of thermoplastic materials (based on the weight of all thermoplastics) is also a means to offset the rising prices of raw materials. Recycled plastics are used for applications such as bumpers or underbody panelling - that is, components with relatively low functional and material requirements and parts with no safety or functional relevance (Daimler, 2011).

The current treatment practices for waste glass-fibre-reinforced plastics are incineration, landfilling after treatment or recycling in concrete/cement composites in the construction sector (Asokan et al., 2009). The challenge in mechanical recycling of fibre-reinforced plastic composites is that it includes regranulation of sprues or other parts, which shortens the glass fibres, changes their alignment and alters the atomic/crystal structure of the material. These changes to the material properties are aggravated with every recycling cycle. Moreover, material testing for recycled glass-fibre-reinforced plastics is a complex issue (e.g. under life-cycle considerations) (Klimkeit et al., 2011; Yang et al., 2012). This case study is highly innovative. For the first time in an automotive safety-relevant use case, it is shown that technical requirements can be met with mechanically recycled glass-fibre-reinforced composite thermoplastic material, demonstrating that resource value is conserved and not downcycled.

\section{The Zerowin approach and its application within the automotive sector}

The zero waste approach (Curran and Williams, 2012; Williams et al., 2011) was applied to the automotive sector and an assessment was made to see if - and how - the overall goals of the Zerowin project could be reached. The overall goals are

to reduce greenhouse gas (GHG) emissions by at least 30\%

to achieve waste prevention by reuse or recycling of $70 \%$ of total weight

to reduce fresh water utilisation by $75 \%$. 
The selected safety-relevant component was manufactured from mechanically recycled material. Improvements reached in different scenarios were measured using life-cycle analysis (LCA) and then compared to the baseline scenario of production of the component using primary PET-GF35. The goal of the case study was to establish an industrial network to secure the long-term supply of recycled PET-GF35 material and to overcome technical and organisational barriers for the use of recyclate in high-requirement applications.

To implement the Zerowin approach of designing waste out of the production process and optimising environmental, social and economic benefits in the automotive sector, the following four goals were established.

Goal A - development of the component consisting (partly) of plastics recyclate (product concept).

- Goal B - elaboration of material testing processes, specifications and identification of critical process parameters for the recyclate.

- Goal C - establishment and design of a recycling process and changes in the production process of the component.

- Goal D - design and establishment of an industrial network, manufacturing of prototypes and starting mass production of the component.

\subsection{Methodology and scope of the case study}

The Zerowin framework as developed in the Zerowin vision (Curran and Williams, 2012; Williams et al., 2011) and the Zerowin production model (Arnaiz et al., 2011) was addressed by the case study through zero waste and eco-design (IEC, 2009) as key approaches of the Zerowin project. The scope of eco-design within Zerowin includes design for (material) recycling, design for minimal production of waste and design for production waste recycling (Williams et al., 2011).

The composite plastic waste (formerly incinerated) was to be reutilised in its original, safety-relevant use case. This required a redesign of the component (eco-design: design for material recycling and design for production waste recycling), which also required major changes to the production process. The production process itself was adapted in order to eliminate waste production (eco-design: design for minimal production of waste).

To get the component with recycled material into practice, four interdependent fields of action were identified - material properties, component design, production process and material/component specification. The use of recyclate as production input, thereby replacing an established and well-known primary material, entailed changed material properties which changed the whole 'system of the component'. The altered material properties set other parameters for component design because they determine possible geometries of the component. The component design therefore had to address those restrictions. The altered material properties also resulted in changes to the production process: injection moulding points were changed, another moulding process had to be introduced (hot-channel instead of cold-channel moulding) and a recycling process for the sprues was implemented and integrated into the production. Since the production process had to be changed, other parameters for possible component designs were set; for example, hot- instead of cold-channel moulding enabled other injection points and therefore geometries of the component.

The production process thus had to be appropriate to implement component design into a physical product. The altered material properties had to fulfil the material and component specifications of the OEMs and the OEMs finally had to release them for serial production. The tier 1 supplier had to elaborate suitable testing procedures and perform a series of tests on the material and sample parts in order to prove compliance with the material and component specifications. Furthermore, the OEMs set the specifications for the braking system and the component. The tier 1 supplier then had to develop the component with recyclate share and then change the production process in order to fulfil the functionalities and requirements demanded by OEMs. Figure 2 shows an overview of these interdependencies.

The Zerowin project targets industrial networks, so each level of the network - the micro-level (process optimisation), the meso-level (optimisation of bundles and arrangements of processes) and the macro-level (beyond the boundary of a single firm: by-product exchange, utility sharing and planning/ management of the network) - has to be assessed (Arnaiz et al., 2011). Figure 3 shows how the case study addressed these levels.

For by-product exchange, possible sources of PET-GF35 recyclate were assessed. Supply for this safety-relevant use case has requirements on the material sources, originating from, for example, the innovation cycles of the component. The tier 1 supplier develops it for OEMs by adapting a design platform to individual requirements. This means that the rough design of the component is determined with this platform and only customer-specific adaptions are implemented. Such a platform is regularly used for a period of 9-16 years and thus the availability of the recyclate has to be secured over a long time period. Additionally, material properties are altered more with each recycling cycle - only PET-GF35 that has been recycled once is released for serial production by the tier 1 supplier which makes the traceability of the origin/source mandatory. The main customer of the material is the automotive sector; worldwide, less than 20 additional companies use PET-GF35 for manufacturing components and products. 
Waste and Resource Management

Volume 167 Issue WR4
Recycling glass-fibre-reinforced

plastics in the automotive

sector

Regenfelder, Faller, Dully et al.

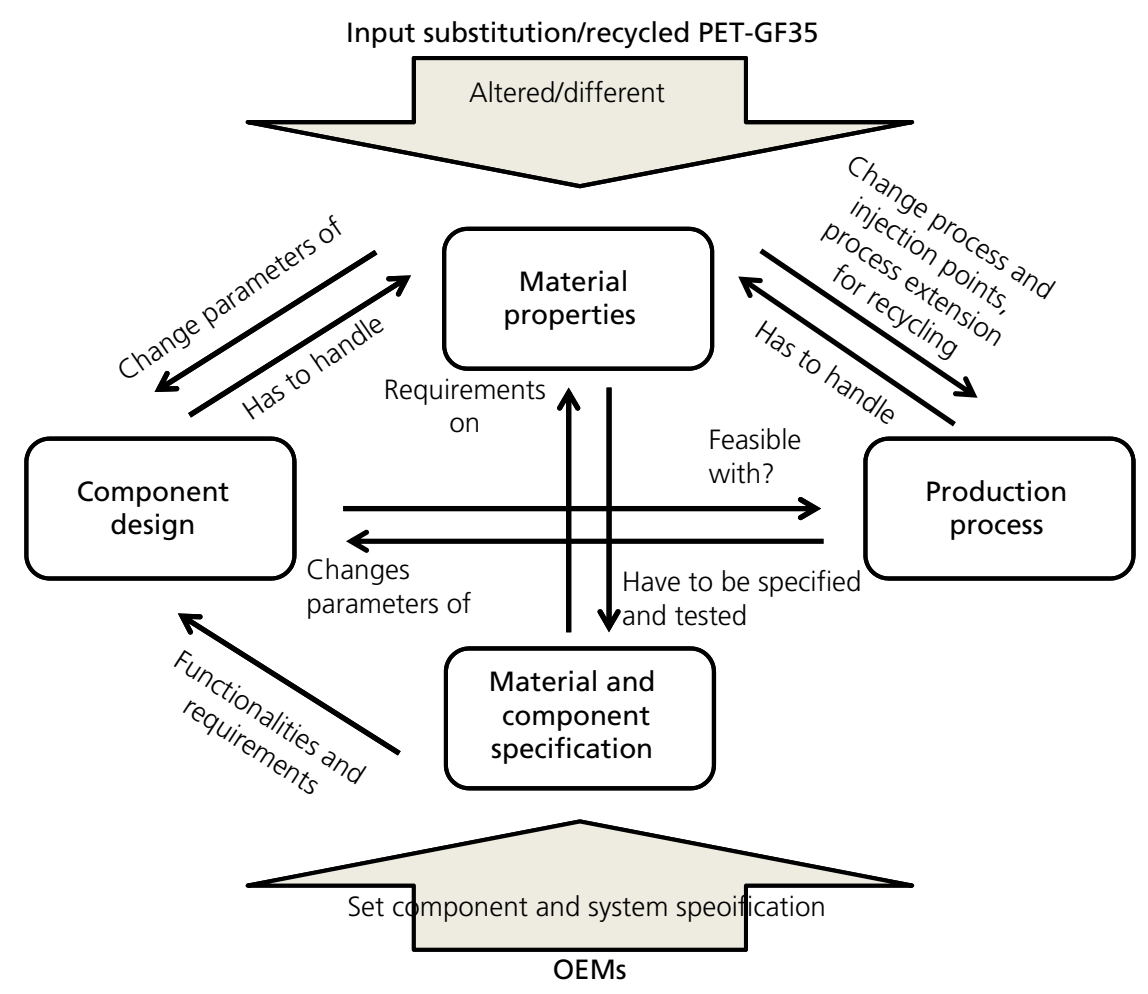

Figure 2. Interdependencies for the implementation of this case study

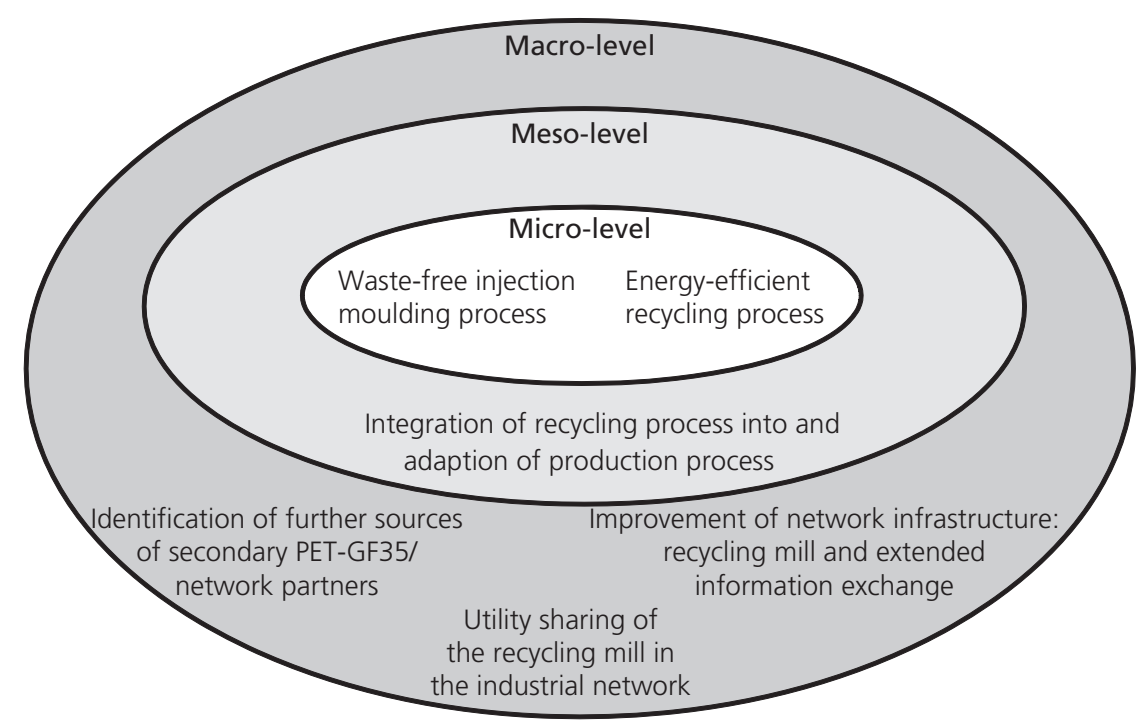

Figure 3. Levels of scope and optimisations in this case study 
Another source for PET-GF35 was identified in ELVs (i.e. used PET-GF35 components).

To implement these approaches into the practice of an industrial network, a conceptual scenario was developed and three possible material loops (loop 1A, loop 1B and loop 2) were investigated. As noted earlier, PET-GF35 is mainly used in the automotive sector and therefore this sector was chosen for possible materials exchanges and network partners. The loops differ from each other with regard to the degree of cooperation with external companies.

(a) Within loop 1A, a recycling process was established to recycle the sprues from cold-channel injection moulding of the considered component with virgin PET-GF35 at the plastic components manufacturer. After regrinding the contamination-free collected sprues in the recycling mill (which can be operated by external firms or by the manufacturer itself), the recyclate granulate is mixed with virgin plastics granulate and then moulded with hotchannel injection moulding machinery.

(b) Loop 1B represents an extension of loop 1A as it considers sprues from other plastics manufacturers that produce components from PET-GF35. The recycling mill established in loop 1A enables the use of plastic waste from other manufacturers in order to produce the requested components. However, to be able to use materials and by-products from different companies, the plastics components manufacturers had to ensure that the quality specifications demanded by the tier 1 supplier were strictly met. One tier 2 supplier was chosen as a potential first additional supplier.

(c) Loop 2 deals with post-consumer plastic waste. This waste can be collected when dismantling ELVs and recovering the relevant used components. However, most ELV recyclers shred full cars after removing components that contain hazardous substances (batteries, petrol, oil, brake fluid, etc.) and only then can the recovery of mixed plastics take place. Thus, in order to implement loop 2, additional research on traceability (e.g. through a radiofrequency identification (RFID) tracking method) and a change to the current recycling concept of the major ELV recyclers (more dismantling than shredding as a first step) would be necessary. This loop involves more risk to material quality and potential difficulties than the others.

The environmental benefits of this case study were proofed by LCA that compared the produced safety-relevant component made out of virgin plastic (termed the baseline scenario) and its production from recycled plastic or with a share of recycled plastic (the improved scenario). The economic focus is on materials costs (savings) versus (increased) infrastructure costs. Social indicators were assessed with the categories of a social
LCA (Obersteiner et al., 2012). The manufacturing processes included in the baseline scenario with their inputs (I) and outputs $(\mathrm{O})$ were

production of virgin material (electricity, water, oil, glass fibres (I); virgin PET-GF35 (O))

injection moulding process for component manufacture (electricity, PET-GF35 (I); components (O))

integration and manufacture of the braking system (the considered component, other components (I); braking system $(\mathrm{O})$ )

integration of the braking system into automobiles (braking system, other components (I); assembled cars (O)).

Only the direct manufacture of the component - the injection moulding - is the process of concern in the baseline scenario since other processes remained unchanged in the later introduced pilot scenario for the first serial production. When producing the component with recycled material, the scope was widened to include the additional processes of

collection of sprues (contamination-free sprues $(\mathrm{O})$ )

- regranulating process with mixing of virgin materials and recyclate (contamination-free sprues, electricity (I); recyclate granulate or mixture of virgin materials and recyclate (O)).

The system boundaries were limited to the safety-relevant component. The boundaries include production of the material, production of the component and disposal of corresponding sprues. The processes included in the LCA are shown in Figure 4 for the baseline scenario and in Figure 5 for the production of prototypes/first serial production. A functional unit is defined as $1 \mathrm{~kg}$ of the component (Obersteiner et al., 2012, 2013).

The main driver for attaining environmental benefit is the substitution of primary material with PET-GF35 recyclate. Regarding the environmental impact, especially carbon dioxide emissions, the production of primary PET-GF35 is the most detrimental (Obersteiner et al., 2013).

\subsection{Results}

This case study led to the establishment of an industrial network and the start of serial mass production of the safetyrelevant component of the braking system with a share of recyclate. For the first serial production, a recyclate share of 33\% was chosen and this is produced via the industrial network of loop 1A. The former production waste is $100 \%$ recycled and dust loss from milling accounts for only $5 \%$ of the weight of the sprues. The altered injection moulding process no longer produces waste. Therefore, prevention of waste through reuse and recycling is $95 \%$, GHG emissions are reduced by $34 \cdot 3 \%$ and fresh water 
Waste and Resource Management Volume 167 Issue WR4
Recycling glass-fibre-reinforced

plastics in the automotive

sector

Regenfelder, Faller, Dully et al.

Ecosphere

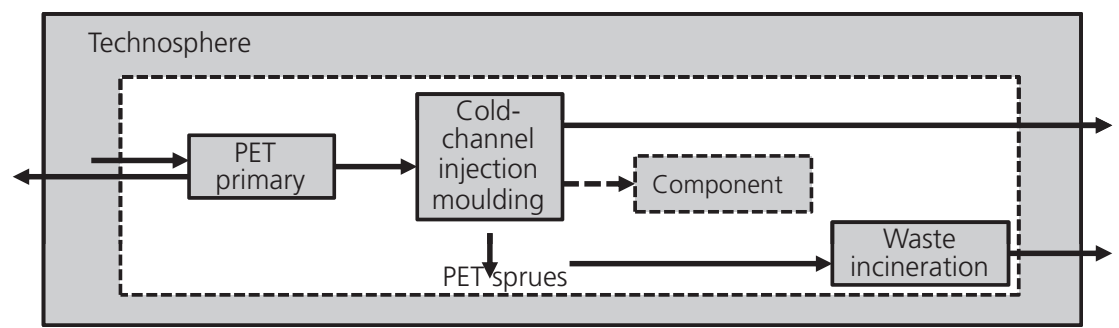

Figure 4. System boundaries in the baseline scenario (Obersteiner et al., 2013, with adaptions)

consumption is decreased slightly $(15 \%)$. This means that, in current serial production, the Zerowin waste goal is not only fulfilled but is strongly exceeded and the GHG goal is met; the water goal is, however, not met because of the additional energy consumption of the recycling process (milling) (Obersteiner et al., 2012, 2013). Moreover, developed and tested prototypes demonstrated technical feasibility of the component with even higher shares of recyclate of $50 \%, 70 \%$ or even $100 \%$ (Faller et al., 2013). This means that two out of the three overall Zerowin goals were fulfilled by serial production or prototypes.

The component with a $33 \%$ recyclate share is in serial mass production: one large OEM is already involved and several new projects with other OEMs are planned. For the first pilot customer OEM, a production of 600000 parts per year was scheduled and started in October 2012.

Economically, the tier 1 supplier is expecting financial benefits. Since PET-GF35 virgin material costs about $€ 3600 / \mathrm{t}$ and is thus a high-value plastics material, its substitution with secondary material is a cost-saving measure. The infrastructure costs (recycling mill plus process adaption costs) are expected to be more than compensated for by the material cost savings during the runtime of components with recyclate content. The case study's results yield a competitive advantage because the component, as part of the braking system, faces high cost pressure from the OEMs and improvements (e.g. in component design) are meanwhile limited. The amount of virgin material substituted by former waste and the materials savings from the changed moulding process in just one year of production for only one pilot OEM customer amount to about $25 \mathrm{t}$ and consequently significant materials cost savings.

The social LCA showed benefits from the implemented loop 1A for the indicators consumer-public education, local community-public education, local community-job creation and an additional indicator specific to the case study. This latter indicator can be implemented in the workers or society stakeholder group; it deals with the job security that is provided by being on the competitive edge of technology. Other indicators remained unchanged compared to the baseline scenario. In the stakeholder category 'consumer', the only improvement was the undertaking of public education. The case study serves as an example of good practice and assists in public education (Obersteiner et al., 2013).

Regarding the case study specific goals, goal A (development of the component consisting (partly) of plastics recyclate

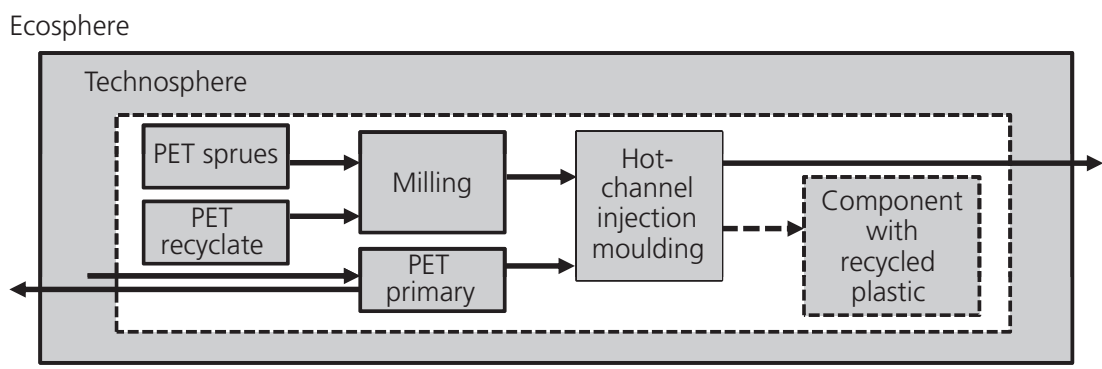

Figure 5. System boundaries for pilot serial production

(Obersteiner et al., 2013, with adaptions) 
(product concept)) was successful. The tier 1 supplier had to define the requirements for the component and the braking system with the pilot OEM customer. This included reengineering of the component since the recycled material had properties differing from those of the virgin material. Among other things, product development had to consider the geometry of the component and the positioning of injection points. The main requirement for the component is to resist defined forces without breaking. For the case study with the recyclate-virgin materials mixture, a new material was used. The employed material was not well known, in contrast to the virgin PET-GF35, and experience in handling recyclates was lacking. Testing procedures proved technical feasibility for a wide range of recyclate shares $(0,10,30,50,70$ and $100 \%)$ if the range of variation in some parameters of the material properties could be reduced while maintaining the same mean values. Mixtures with a content of $30 \% \quad(+3 \%$ positive tolerance) recyclate fulfilled the requirements while mixtures with some other contents faced difficulties in terms of variations in results. Nevertheless, the latter mixtures still complied with the material requirements for the component.

Goal B (elaboration of material testing processes, specifications and identification of critical process parameters for the recyclate) was one of the key issues to enable the use of recycled plastics material for the safety-relevant use case. New material specifications and, accordingly, other testing processes were elaborated. Material properties were tested in a series of examinations and a specification for the material with a $30 \%$ $(+3 \%)$ recyclate share was released for serial production. Only recyclate from traceable sources according to the standard drafts prEN 15343 (DIN, 2005) and prEN 15347 (BSI, 2005) was released for serial production because of the increasingly changing material properties of the recyclate with every recycling cycle. Only recyclate granulate that has passed the recycling loop once was released, otherwise there are too many concerns about variation and fulfilment of mechanical properties. As a critical process parameter for the employability of recycled materials for this safety-relevant component, contaminations of the recyclate with machine oil during the collection and recycling process of the sprues were identified but regarded as manageable.

Goal C (establishment and design of a recycling process and changes in the production process of the component) was implemented at the plant of the plastic component manufacturer and is serial production ready. The recycling process had to be designed and integrated into the overall production process, which itself had to be adapted. Development of the recycling process for reprocessing the sprues and producing appropriate recyclate included the unmixed collection of sprues, grinding of collected material, dosed mixture from virgin and recycled materials, drying of the mixture and transportation to the injection machine. The injection moulding process itself was changed. Instead of cold-channel injection moulding, a hot-channel injection moulding technique is now used. This means that no sprues are now accumulated and other injection points are feasible. Waste has thereby been designed out of the production process. Figure 6 shows the modifications implemented in the production process and the integration of the recycling process.

Goal D (design and establishment of an industrial network, manufacturing of prototypes and starting mass production of the component) addresses practical implementation of the results of goals A-C in an industrial network. Several scenarios for industrial networks were assessed and three possible loops were identified. Prototypes and the first serial production were implemented via loop 1A (improved scenario). Loop 1B was investigated but has not yet been implemented for serial production. It could be implemented when additional sprues are needed to ensure the recyclate supply from other plastic components manufacturers that use PET-GF35. Loop 2 was assessed but not implemented as ELVs are shredded and only the recovery of mixed plastics is feasible. Moreover, traceability of the material is not ensured. Serial production of the component with a recyclate share of $33 \%$ began in October 2012 via loop 1A; one large OEM is already involved and several new projects with other OEMs are planned.

\section{Economic implications from the case study: lessons learned}

The use of recycled plastic materials in the manufacturing of products adds complexity to production: there is uncertainty about

- the availability of recycled materials streams where large stocks of recycled materials are required to meet demand

the quality and contamination of recycled material

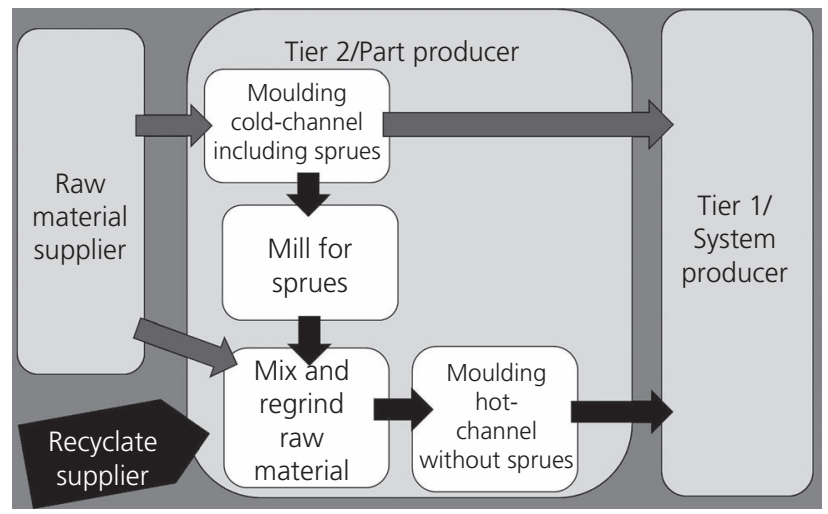

Figure 6. Recycling and production process 
Waste and Resource Management

Volume 167 Issue WR4
Recycling glass-fibre-reinforced

plastics in the automotive

sector

Regenfelder, Faller, Dully et al. collection and reverse logistics

recycling infrastructure and processes

variations in material properties (Allwood et al. 2011; Brennan et al., 2002; Dillon, 1999; Pehlken and Thoben, 2011; Qu et al., 2006, Yang et al., 2012).

As noted previously, there are interdependencies between material and component specifications, component design, material properties and the production process. This is an important complexity driver. Using recycled PET-GF35 for a safety-relevant component is therefore not just an issue of input substitution - it is an interplay of technological (product development, production process modification, recycling process), organisational (security of supply, network infrastructure) and economic (material cost savings versus adjustment costs, planning horizons) factors that result from the substitution of input primary material. Product development and production process design need to be strongly linked in order to be able to use recycled material as input. This case study became an economic success only because the involved companies succeeded in handling each of these four fields of action and their interdependencies.

The properties of glass-fibre-reinforced plastics degrade with every recycling cycle. Therefore, only recycled material from defined and traceable sources can be used to prevent uncontrollable changes in material having passed through more than one recycling cycle. In addition, materials supply has to be guaranteed for the whole runtime of the component's design platform, which is longer than a decade. Switching back to virgin materials if recyclate is not abundantly available would cause high adjustment costs.

Whereas low-requirement automotive components can be manufactured with 'standard' recyclate from secondary raw materials brokers, this market-based procurement for highrequirement components might be inappropriate and more stable relations within industrial networks have to be developed to ensure availability and quality of material, as has been demonstrated in this case study. Industrial networks can thus be seen as a tool to enable increased use of recyclates in the automotive sector and help prevent plastic materials from becoming waste, especially for applications that cannot be made with recyclate from unknown sources and with unknown quality.

Improvement in the resource efficiency of the component's manufacture was enabled by close cooperation among the network partners. This is especially true for the tier 1 supplier and the plastic component manufacturer, who exchange more information about component development and the production process than in the baseline scenario and share the utility of the recycling infrastructure in the network. This is a step towards a symbiotic business model between manufacturers and recyclers (Jonsson et al. 2011).

\section{Conclusion and outlook}

This case study has shown the technical feasibility of the mechanical recycling of short glass-fibre-reinforced PET for an automotive component by applying the Zerowin framework. A safety-to-life component of the braking system was developed, material specifications were elaborated, an industrial network for production was established and the safety-relevant component for the braking system with a recyclate share of 33\% was transferred to serial mass production. Primary material input was substituted with secondary material, resulting in significant environmental benefits and materials cost savings. Industrial networks can thus be viewed as a tool for securing the supply and quality of a high-requirement engineering plastics recyclate.

The substitution of primary material in a component with high technical requirements appears to be more than merely input substitution - product development, production processes and specifications are all affected by changed material properties. Handling this increased complexity requires organisational capability to coordinate a network in which all involved firms cooperate and exchange more information than is usual in the automotive supply chain.

The prototypes manufactured in this case study demonstrated feasibility for even higher recyclate shares for the component than the currently used $33 \%$. This could lead to increased recyclate shares for further serial projects, depending on the security and availability of supplies of recycled material.

This case study demonstrated the application of recyclate for a highly safety-relevant use. This could help to overcome reservations in the automotive sector about recycled materials for function-relevant use cases and unlock new possibilities for the application of recycled plastics.

\section{Acknowledgement}

The research leading to these results received funding from the European Community's Seventh Framework Programme (FP7/2007-2013) under grant agreement No. 226752.

\section{REFERENCES}

Allwood J, Ashby M, Gutowski T and Worrell E (2011) Material efficiency: a white paper. Resources, Conservation and Recycling 55(3): 362-381.

Arnaiz S, Gauo M, Wolf M, Osório-Peters S and Durão V (2011) Deliverable 5.1. Production Model Developed. Zerowin project, Vienna, Austria.

Asokan P, Osmani M and Price A (2009) Assessing the recycling potential of glass fibre reinforced plastic waste in concrete and cement composites. Journal of Cleaner Production 17(9): 821-829.

BMW AG (2011) Sustainable Value Report 2010. BMW AG, Munich, Germany. 
Brennan LB, Isaac DH and Arnold JC (2002) Recycling of acrylonitrile-butadiene-styrene and high-impact polystyrene from waste computer equipment. Journal of Applied Polymer Science 86(3): 572-578.

BSI (2005) prEN 15347: Draft, plastics, recycled plastics. Characterisation of plastics wastes. BSI, London, UK.

Curran T and Williams ID (2012) A zero waste vision for industrial networks in Europe. Journal of Hazardous Materials 207-208: 3-7.

Daimler AG (2011) Environmental Certificate for the New $B$-Class. Mercedes-Benz Cars, Stuttgart, Germany.

Dillon P (1999) Recycling infrastructure for engineering thermoplastics: a supply chain analysis. Proceedings of the 1999 IEEE International Symposium on Electronics and the Environment, Danvers, MA, USA, pp. 198-203.

DIN (Deutsches Institut für Normung) (2005) DIN prEN 15343: Draft, draft document - plastics - recycled plastics plastics recycling traceability and assessment of conformity and recycled content. DIN, Berlin, Germany.

EC (European Community) (2000) Directive 2000/53/EC of the European Parliament and of the Council of 18 September 2000 on end-of-life vehicles. Official Journal of the European Communities L269: 34-42.

EC (European Community) (2009) Regulation (EC) No 443/2009 of the European Parliament and of the Council of 23 April 2009 setting emission performance standards for new passenger cars as part of the Community's integrated approach to reduce $\mathrm{CO}_{2}$ emissions from light-duty vehicles. Official Journal of the European Union L140: 1-15.

EC (European Community) (2012) Proposal for a Regulation of the European Parliament and of the Council Amending Regulation (EC) No 443/2009 to Define the Modalities for Reaching the 2020 Target to Reduce $\mathrm{CO}_{2}$ Emissions from New Passenger Cars. EC, Brussels, Belgium.

Faller J, Dully S, Perthes $\mathrm{H}$ et al. (2013) Deliverable 6.B.5. Prototype of an Automotive Component. Zerowin project, Vienna, Austria.

Hopewell J, Dvorak R and Kosior E (2009) Plastics recycling: challenges and opportunities. Philosophical Transactions of the Royal Society B 364(1526): 2115-2126.

IEC (International Electrotechnical Commission) (2009) IEC 62430: Environmentally conscious design for electrical and electronic products. IEC, Geneva, Switzerland.

Jonsson C, Felix J, Sundelin A and Johansson B (2011) Sustainable production by integrating business models of manufacturing and recycling industries. In Proceedings of the 18th CIRP International Conference on Life Cycle Engineering Glocalized Solutions for Sustainability in Manufacturing, Braunschweig, Germany (Hesselbach J and Herrmann C (eds)). Springer, Berlin, Germany, pp. 201-206.

Jovane F, Westkämper E and Williams D (eds) (2009) The ManuFuture Road. Springer, Berlin, Germany.

Klimkeit B, Castagnet S, Nadot Y et al. (2011) Fatigue damage mechanism in short fibre reinforced PBT + PET GF30. Materials Science and Engineering 528(3): 1577-1588. Lazarevic D, Aoustin E, Buclet N and Brandt N (2010) Plastic management in the context of a European recycling society: comparing results and uncertainties in a life cycle perspective. Resources, Conservation and Recycling 55(2): 246-259.

Obersteiner G, Beigl P, Pertl A and Scherhaufer S (2012) Deliverable 7.2. Report on Assessments of Pilot Cases: Midterm Assessment. Zerowin project, Vienna, Austria.

Obersteiner G, Beigl P, Pertl A and Scherhaufer S (2013) Deliverable 7.3. Report on Assessments of Pilot Cases: Final Assessment. Zerowin project, Vienna, Austria.

Pehlken A and Thoben KD (2011) Contribution of recycling processes to sustainable resource management. In Proceedings of the 18th CIRP International Conference on Life Cycle Engineering - Glocalized Solutions for Sustainability in Manufacturing, Braunschweig, Germany (Hesselbach J and Herrmann C (eds)). Springer, Berlin, Germany, pp. 465-469.

Plastics Europe, European Plastics Converters, European Plastics Recyclers and European Association of Plastics Recycling, and Recovery Organisations (2012) Plastics - The Facts 2012 An Analysis of European Plastics Production, Demand and Waste Data for 2011. Plastics Europe, Brussels, Belgium.

Qu X, Stuart Williams J and Grant E (2006) Viable plastics recycling from end-of-life electronics. IEEE Transactions on Electronics Packaging Manufacturing 29(1): 25-31.

Volkswagen AG (2012) Nachhaltigkeit - Bericht 2011. Volkswagen AG, Wolfsburg, Germany.

Williams ID, Curran T and Ongondo F (2011) Deliverable 1.3B. Zerowin Commonly Agreed Vision Paper. Zerowin project, Vienna, Austria.

Yang Y, Boom R, Irion B et al. (2012) Recycling of composite materials. Chemical Engineering and Processing 51: 53-68.

\section{WHAT DO YOU THINK?}

To discuss this paper, please email up to 500 words to the editor at journals@ice.org.uk. Your contribution will be forwarded to the author(s) for a reply and, if considered appropriate by the editorial panel, will be published as discussion in a future issue of the journal.

Proceedings journals rely entirely on contributions sent in by civil engineering professionals, academics and students. Papers should be $2000-5000$ words long (briefing papers should be 1000-2000 words long), with adequate illustrations and references. You can submit your paper online via www.icevirtuallibrary.com/content/journals, where you will also find detailed author guidelines. 